http://dx.doi.org/10.12795/PH.1990.v05.i01.14

\title{
Precisiones sobre el concepto de oración
}

\author{
Esperanza Rocío Alcaide Lara
}

0. Abordamos en este estudio un tema fundamental para la Sintaxis y la Lingüística en general: La Oración, considerada, hasta prácticamente hoy, punto de partida de toda labor investigadora dentro de esta disciplina.

Nuestro interés por este tema surgió a raíz de la investigación que llevamos a cabo en nuestra tesis de Licenciatura acerca de un tipo de construcción muy usual en la lengua española, que nosotros dimos en llamar Oración de Predicado no verbal, cuyas características esenciales enumeraremos más adelante.

Esta, aunque ha sido una de las cuestiones importantes que hay que tratar en el estudio de nuestra lengua por sus diversas implicaciones, no ha sido analizada en casi ninguna de las gramáticas, manuales y libros de la materia. Sólo unos pocos autores hacen referencia a las mismas, pasando sobre ellas como «sobre ascuas», debido a las dificultades que su propia naturaleza encierra.

Una de estas dificultades está en dirimir qué tipo de unidad lingüística es la conformada por la Oración de Predicado no verbal. Nosotros pensamos que, como su nombre indica, entra dentro de la unidad Oración. Sin embargo, para demostrar esto, tuvimos que replantearnos una cuestión fundamental: ¿Qué es la Oración?. Pronto nos dimos cuenta de que, a pesar de que éste era un asunto del que se habían ocupado no pocos lingüistas, desde Dionisio de Tracia o Prisciano, hasta autores tan de nuestros días, como J. M. Lope Blanch, G. Rojo o S. Gutiérrez Ordóñez ${ }^{1}$, directa o indirectamente, como en nuestro caso, el concepto de oración no estaba claro. Es más: se conformaba como una confusa maraña de opiniones tomadas desde muy diferentes criterios y métodos. Ello hizo que nuestra preocupación por el asunto fuera en aumento y nos dispusiéramos a emprender una investigación que tiene su comienzo aquí.

\footnotetext{
${ }^{1}$ Este último cuestiona el concepto de Oración en su artículo «¿Es necesario el concepto "oración”?»,
} R. S. E. L., 14, 1984, pp. 245-270. 
1. Tres han sido los criterios que, a lo largo de la Historia lingüística, se han tomado como punto de partida para definir la Oración: el lógico, el semántico o psicológico, y el formal.

Si hacemos un breve repaso al modo en que ha sido considerado este concepto a lo largo del tiempo, veremos que ya E.A. de Nebrija, F. Sánchez de las Brozas y G. de Correas caracterizaban la Oración como una construcción formada por nombre y verbo ${ }^{2}$.

En 1558, el Licenciado Villalón diferencia, aunque no muy claramente, entre cláusula y oración: «...Ay differencia entre clausula y oraçión. Que oraçion, a lo menos perfecta, se compone por la mayor parte de persona que haze alguna obra: y de verbo: y de persona en quien denota passar, o hazer aquella obra del verbo (...) Y digo que clausula es a las vezes una oraçion sola y otras vezes es un ayuntamiento de muchas oraçiones: las cuales todas juntas espresan y manifiestan cumplidamente el conçibimiento del hombre en el proposito que tiene tomado para hablar» ${ }^{3}$, criterio que adoptarán Juan de Iriarte en el siglo XVIII (aunque sustituye los términos cláusula y oración, por el de cláusula y frase) y A. Bello en el XIX, quien utilizará los términos oración y proposición ${ }^{4}$.

Este último ha influido en autores como A. Alonso y P. Henríquez Ureña, R.A. de la Peña, J. Roca Pons, C. Hernández Alonso, M. Seco, J. Alcina y J.M. Blecua, y J. Escarpanter, entre otros, aunque en opinión de J.M. Lope Blanch, en éstos «ha pesado más que la opinión de Bello, la de L. Bloomfield y otros gramáticos de lengua inglesa seguidores suyos» ${ }^{5}$.

La Gramática de Port-Royal tomará un punto de vista lógico para caracterizar a este elemento, sobre el cual nos dice que «al juicio que nosotros hacemos de las cosas, como cuando digo "La Tierra es redonda" se llama Proposición» ${ }^{6}$. Estos gramáticos, al igual que lo hace en España el Padre Benito de San Pedro, utilizan términos propios de la Lógica, por lo cual podemos entender que, para ellos, Proposición es la expresión verbal de un juicio.

Esta misma línea siguen los neogramáticos del siglo XIX, aunque mezclada con la corriente psicologista imperante en la época. Así, tenemos ejemplos como H. Paul o W. Wundt. Para éste último, «el proceso del análisis aperceptivo deriva el juicio que, en el discurso, se expresa por la proposición»?

${ }^{2}$ Cfr. G. Correas, Arte de la lengua española castellana, ed. de E. Alarcos García, (R.F.E., Anejo LVI, 1954), p. 137, donde el autor la define como «el sentido y rrazón que se haze con nombre i verbo conzertados en numero i persona, i se adorna ó no se adoma con la partezilla, i con sus propias espezies de partes i casos».

${ }^{3}$ Licenciado Villalón, Gramática castellana, (Madrid, CSIC, 1971), p. 85.

${ }^{4}$ Cfr. A. Bello y R. J. Cuervo, Gramática de la lengua castellana, $8^{\mathrm{a}}$ ed. (Buenos Aires, Sopena 1970), p. 129.

5 J. M. Lope Blanch, El concepto de oración en la lingüística española, (México, Universidad Autónoma de México, 1979), p. 35.

${ }^{6}$ R. Donzé, La Gramática general y razonada de PortRoyal, (Buenos Aires, Eudeba, 1970) p. 134.

${ }^{7}$ G. Wundt, Compendio de Psicología, Trad. de J. González Alonso, (Madrid, La España Moderna, 1896), p. 352. 
En el siglo XX, se utilizan todos estos criterios, sin llegar a un acuerdo sobre el concepto de oración. Un ejemplo de ello lo tenemos en los siguientes autores: A. Gardiner seguirá en una línea psicologista, mientras F. de Saussure lo circunscribirá al habla (teoría que sigue Piccardo), y L. Hjelmslev pensará que no tiene carácter linguíistico ya que, según éste, todavía no se ha dado una caracterización satisfactoria desde el punto de vista formal.

Una postura intermedia entre los dos últimos autores mantendrá E. Coseriu, para quien, como forma ideal y hecho linguiístico, la oración pertenece a la lengua, y, como realización, como utilización concreta e individual de esa estructura ideal, pertenece al habla.

Casi todos los criterios se mueven en el aspecto lógico (como es el caso de $\mathbf{R}$. Seco), en el psicológico (como ocurre con $\mathbb{R}$. Lenz) o en el semántico (campo en el que entran definiciones como las de K. Bühler, A. Alonso y P. Henríquez Ureña o G. Carrillo Herrera) ${ }^{8}$.

Posturas puramente gramaticales son las que adoptan lingüistas como L. Bloomfield, Ch. Hockett o V. Bröndal.

El primero propone un concepto de oración fundamental sobre bases distribucionales: Oración sería toda forma lingüística no incluida en una construcción más amplia.

Tanto Ch. Hockett como V. Bröndal intentan, asimismo, un tipo de definición formal o funcional. Para Hockett «a sentence is a grammatical form which is not in construction with any other grammatical form: a constitute which is not a constituent»9. V. Bröndal la considera un conjunto sintáctico completo y relativamente autónomo desde el punto de vista funcional. Coincidiendo con ambos lingüistas tenemos a A. Meillet ${ }^{10}$.

La Gramática Genero-Transformativa en general concibe la oración como el símbolo inicial de su sistema de reglas (como unidad, por tanto, en posición absoluta), dotada de una estructura definida y capaz de recibir una interpretación semántica y otra fonética. De estos dos últimos aspectos se encarga el componente semántico y el fonológico respectivamente.

${ }^{8}$ Debido a la propia naturaleza y extensión de este trabajo no considermos oportuno detenernos en cada uno de estos autores por separado. De todas formas, para mayor claridad, cfr. R. Lenz, La oración y sus partes (Madrid, R.F.E., 1925); R. Seco, Manual de gramática española (Madrid, C.I.A.P., 1930), p. 17; K. Bühler, Teoría del lenguaje (Madrid, Revista de Occidente, 1979), p. 377; A. Alonso y P. Henríquez Ureña, Gramática castellana, ed. 29ª (Buenos Aires, Losada, 1983, Vol. I) pp. 26-28.

${ }^{9}$ Ch. Hockett, A course in modern Linguistics (New York, The Mcmillan Company, 1958), p. 199.

${ }^{10}$ Otra serie de autores mezcla los distintos criterios, como por ejemplo O. Jespersen, que adopta el lógico, el semántico y el formal. Para este lingüista, en la oración la noción de sentido completo va ligada a la posibilidad de una secuencia de formar un todo por sí misma y de poder ser emitida aisladamente. Así distingue entre nexus (estructura con un verbo en forma personal) y sentence (enunciado completo e independiente), aspectos que son diferenciados también por la Real Academia en su Esbozo de una nueva gramática de la lengua española (Madrid, Espasa-Calpe, 1973), pero bajo un mismo término: Oración.

S. Gili Gaya, por su parte, habla de tres definiciones de oración: una psicológica, otra lógica y otra gramatical, que están en la línea de los tres criterios que han sido utilizados por los lingüistas anteriores. 
Por otro lado, hay lingüistas que consideran imposible definir la oración. Para A. Cardona-Castro, por ejemplo, es admisible la existencia del concepto oración, pero es imposible definirla porque surgen ejemplos donde, si bien hay independencia sintáctica, no tenemos ni rastro de la binariedad de la que han hablado L. Bloomfield o N. Chomsky, entre otros.

Por su parte, S. Gutiérrez Ordóñez, uno de los últimos autores que se han preocupado de esté tema, llega a la conclusión de que lo verdaderamente importante de definir es el enunciado compuesto de un signo enunciativo (o modos oracionales que nos informan de la actitud del emisor hacia su mensaje) y el esquema sintgmático (dominio propio de la Sintaxis). Este es una unidad con función propia y específica (la función comunicativa) y la unidad superior de la que se ocupa la citada parcela lingüística.

Según Gutiérrez Ordóñez, el concepto de oración sólo es aceptable y necesario cuando se equipara al de frase («secuencia caracterizada por la presencia de un elemento más sus términos subordinados $»^{11}$ ). Por consiguiente, para este autor la oración es equivalente o variante contextual de la frase verbal, tomada ésta última en el mismo sentido en que nosotros tomamos el de Sintagma Verbal.

2. Al hacer anteriormente el recorrido histórico a través del concepto de oración, hemos encontrado una serie de rasgos que se han imputado al mismo. En todo este conjunto de rasgos están presentes los diferentes criterios tomados a la hora de definir dicho concepto, a saber, el lógico, el psicológico, el semántico y el formal.

Si nos atenemos a un criterio gramatical o sintáctico, es lógico rechazar todas aquellas características que caen fuera de este ámbito, como son las siguientes:

- Poseer autonomía semántica.

- Ser la expresión de un juicio.

- Equivaler a la expresión de una unidad de intención.

Así pues, nos quedamos, de momento, con las que siguen un criterio formal, como:

- Ordenación de palabras.

- Autonomía sintáctica.

- Estructura Sujeto - Predicado.

- Presencia de un verbo en forma personal.

- Curva de entonación característica.

Si sometemos cada uno de estos rasgos a estudio, podemos observar que, a excepción del primero ${ }^{12}$, todos ellos plantean problemas para erigirse en el específico y característico de la oración.

${ }^{11}$ S. Gutiérrez Ordoñez, op. cit., p. 269.

${ }^{12}$ El primer rasgo no presenta problemas, pues la oración es una unidad de nivel superior a la palabra, $y$, por lo tanto, las incluye: Es una combinación de las mismas. 
Así, la autonomía sintáctica, si bien pudiera parecer, a primera vista, el rasgo por excelencia de la oración, no es en absoluto el más viable para caracterizar a esta unidad, porque si es así, ¿qué haremos en el caso de las subordinadas o de las interordinarias como en los siguientes ejemplos?:

\section{/1/ Siéntate donde te parezca mejor.}

12/ Si vienes mañana, verás a tu hermano Pedro.

¿Les negaremos su condición de oración?, ¿qué tipo de unidades serían entonces? Como vemos, este requisito se cumple en unos casos y en otros no, por lo cual nos parece claramente insuficiente.

En cuanto a la estructura Sujeto - Predicado (entendida generalmente como la relación entre un SN y un SV) como definitoria de la oración, sólo se adapta a las lenguas que poseen este tipo de construcción. Por otro lado, incluso en éstas surge un problema: La presencia de las llamadas oraciones unimembres, tan frecuentes en lenguas como la española.

Muchos han sido los autores que han considerado que el rasgo característico de la estructura oracional es el de la presencia de un solo verbo en forma personal, pero tenemos razones obvias para no considerarlo así.

Por ejemplo, en casos de secuencias como las siguientes:

/3/ Va a trabajar cuando quiere.

/4/ Aunque llueva, iremos de excursión.

tenemos dos verbos que están conjugados en forma personal.

Ambos ejemplos responden a lo que se ha dado en llamar tradicionalmente «Oración compuesta». Pero si seguimos aceptando la utilización de esta denominación para este tipo de construcciones, rechazamos automáticamente rasgos como el mismo que estamos tratando (la presencia de un sólo verbo en forma personal) y, además, el rasgo que propugna la autonomía sintáctica para la oración.

Por ello, sería más coherente aceptar la idea de que este tipo de estructuras se sitúa en un nivel superior al de la oración entendida al modo tradicional. Es decir, habría que entenderla como una unidad compuesta de oraciones, así como las oraciones se componen de sintagmas, y éstos, de palabras.

De todas formas, y en relación con esto, debemos señalar que casos como el /3/ pueden tener explicación a partir de la Teoría de la Traslación de L. Tesnière ${ }^{13}$. De manera que una estructura oracional como SN+SV puede incluir en su interior otra estructura oracional, que funciona, por traslación, como un complemento cualquiera de la oración primera. Por consiguiente, en una secuencia como $/ 3 /$ tenemos una oración $\mathrm{SN}(\varnothing)+\mathrm{SV}$, cuyo SV está compuesto por un verbo núcleo ( $v a)$ y un Aditamento

${ }^{13}$ Vid. L. Tesnière, Eléments de Syntaxe Structurale, 2ª ed. (París, Klincksieck, 1976). 
conformado, a su vez, por una oración que, por efectos del transpositor cuando, funciona como elemento adnuclear adverbal. Se ha producido, pues, un cambio de categoría gramatical del tipo $\mathrm{V}>\mathrm{Adv}$, con lo cual el segundo verbo no desempeña la función nuclear que le es propia por naturaleza.

Por otro lado, ¿qué ocurrirá con lo que nosotros hemos llamado Oraciones de Predicado no verbal si aceptamos este rasgo? ¿Ocultaremos su propia naturaleza oracional?

Muchos lingüistas así lo hacen, llamando a este tipo de construcciones carentes de verbo explícito, «fragmentos», «frases», «enunciados fragmentarios», etc. (entre este grupo de autores podemos citar a Mª LL. Hernanz, J. M. Brucart, J. Alcina y J. M. Blecua, L. Cortés Rodríguez, etc.).

De todo lo expuesto hasta aquí se deduce que aún no se ha encontrado el rasgo definitorio de un concepto tan complejo como es el de oración. La mayoría de los lingüistas modernos reconocen la necesidad de llegar a dicho rasgo tanto por razones metodológicas, como por razones empíricas.

3. Detrás de todo esto aparece un problema: la unidad de manifestación, completa semánticamente. Ya A. Alonso y P. Henríquez Ureña se plantearon este problema, aunque no llegaron a resolverlo, distinguiendo entre enunciados que son oraciones por la «forma» como

/5/ Mi hermano va a ir al Museo.

constituido por una estructura SN+SV, y enunciados que son oraciones por el sentido, como es el caso de

16/ ¿Dónde está tu hermano?

En el Museo.

Aquí estamos ante una oración que es tal por el sentido, puesto que es independiente sintácticamente y tiene significado autónomo y completo. Pero esto equivaldría a trabajar con dos definiciones de oración y no una, como es de rigor.

Otros lingüistas hablan de unidades de diferentes niveles distiguiendo entre la unidad de manifestación, situada en un nivel discursivo del habla, y la unidad de construcción gramatical, situada en un nivel de la estructura sintáctica.

Entre los autores que así piensan están J. Roca Pons ${ }^{14}$, J. Lyons, J.M. Lope Blanch y G. Rojo, el cual nos dice que «el problema fundamental es si vamos a considerar la oración como una entidad situada en la escala de las unidades gramaticales (esto es, en oposición a otras unidades de esta escala, como por ejemplo la palabra o la frase) o si, por el contrario, va a ser definida como una categoría del discurso» ${ }^{15}$, cuestión que intentaremos dilucidar seguidamente.

14 J. Roca Pons diferencia «la unidad de comunciación y la forma oracional con sujeto y predicado» (Introducción a la gramática, $2^{\mathrm{a}}$ ed. (Barcelona, Teide, 1970), p. 352).

${ }^{15}$ G. Rojo, Cláusulas y Oraciones (Santiago de Compostela, Universidad de Santiago, 1978), p. 16. 
4. Este mismo autor da una clasificación de lo que él llama unidades sintácticas. En ésta distingue entre unidad de comunicación y unidad de construcción. Ya O. Jespersen, S. Stati y L. Zawadowski, autores cuyas tesis aprovecha Rojo, se sitúan en la misma línea. De esta forma, contrapone oración a enunciado. Este último sería una unidad de comunicación al igual que lo define Stati: «De este modo tendríamos que un enunciado debe ser predicativo (o comunicativo en Stati), debe carecer de relaciones sintagmáticos con elementos exteriores a él (independiente en Stati) y ser completo desde el punto de vista semátnico (característica estrechamente ligada a la independencia sintáctica, cfr. Stati)» ${ }^{16}$. Para Rojo, «constituir o no enunciado es independiente de la estructura de la cadena en cuestión» ${ }^{17}$, pues se trata de niveles distintos.

En cuanto a la oración, Rojo acepta la definición de Zawadowski ${ }^{18}$, quedando así establecida como una unidad gramatical que no se limita a la estructura SujetoPredicado, definición que está en la línea tradicional, aunque es más restringida.

Pero, dentro ya del nivel gramatical, contrapone Oración a Cláusula, siendo ésta la unidad con un predicema.

En sus propias palabras, «se caracteriza por presentar una estructura de elementos funcionales agrupados en torno a un predicado» ${ }^{19}$. Este estará conformado por un Verbo en forma personal.

Por otra parte, la oración es presentada como una unidad de nivel superior, formada por dos o más cláusulas que desempeñan una función dentro de ella. «En la oración no existe un elemento obligatorio que nos pueda servir para todas las secuencias pertenecientes a este tipo» ${ }^{20}$. Sigue, pues, el planteamiento de Longacre, quien considera la estructura Sujeto-Predicado la más adecuada para la cláusula, mientras que en la oración se dan funciones distintas, como tesis, antítesis, prótasis, apódosis, etc.

Esta es una vía válida, hasta el momento, para el análisis de la realidad lingüística en sus diferentes vertientes.

Otra es la que presenta un autor como J. M. Lope Blanch. Este clasifica las unidades sintácticas de la siguiente forma:

- Cláusula: «unidad de manifestación (...). No tiene una forma gramatical determinada, puesto que puede estar constituida por una sola palabra -interjección, vocativo, etc.- por un sintagma nominal o adverbial, por una frase, por una oración o por uno o varios períodos» ${ }^{21}$.

16 Idem, p. 24.

${ }^{17}$ Ibídem.

${ }^{18}$ Cfr. L. Zawadowski, «Sentence, its grammatical definition», Linguistics, 72 (1971), pp. 95-112, donde se expone que la oración es la expresión de la predicatividad mediante elementos bien delimitados.

${ }^{19}$ G. Rojo, Aspectos básicos de Sintaxis funcional, (Málaga, Agora, 1983), p. 70.

${ }^{20}$ Idem.

${ }^{21}$ J. M. Lope Blanch, «Unidades sintácticas (Recapitulación)», R.F.E., LXI (1981), pp. 29-63, p. 30. 
- Oración: «sintagma bimembre entre cuyos dos elementos se establece una relación predicativa. Formalmente responde a la fórmula de Bühler [S<----P]» ${ }^{22}$. Ejemplos de ello son:

/7/ Juan come pan.

/8/ Las cuentas, claras.

/9/ ¡Qué bello día!

- Frase: Se organiza en torno a un elemento nuclear, pero no de acuerdo con la estructura [S<----P]. Ejemplo:

/10/ Un limosna, por caridad.

- Prooración: «morfema o sintagma de estructura no oracional que implica reproduce- una oración ya enunciada» ${ }^{23}$. Ejemplo:

$111 /$ ¿Vendrás al campo?

Tal vez

/12/ ¿Cuándo tienes previsto salir?

Mañana por la tarde.

- Período: Está constituido por dos o más oraciones entre las que se establece un sola relación sintáctica, ya sea de subordinación, ya sea de coordinación.

Por ejemplo:

/13/ Si vienes a clase, aprobarás.

/14/ Leí el libro, pero no me gustó.

- Oración compuesta: Cierta clase de períodos en los que uno de los complementos de la oración está conformado por otra oración.

/15/ Te lo diré cuando vuelvas.

De esta forma, podemos deducir que la oración, el período, la oración compuesta, la frase y la prooración pertenecen a un nivel muy distinto del que le corresponde a la cláusula (unidad comunicativa) que equivale a lo que Rojo ha dado en llamar enunciado.

Para Lope Blanch, la oración es la unidad fundamental de la gramática por tres

\footnotetext{
${ }^{22}$ Idem.

${ }^{23}$ Ibídem, p. 23.
} 
razones:

a) Por ser la expresión predicativa con estructura [S<----P] la más usual en el acto de comunicación.

b) Por ser ella la que ha permitido levantar el edificio gramatical.

c) Por ser definida tanto morfológica como sintácticamente.

Podemos observar que esta clasificación, a pesar de que deja como puntos marginales a lo que se da en llamar frase y prooración, como algo secundario en la lengua, es bastante completa y recoge, distinguiéndolos, los dos sentidos que tradicionalmente se ha atribuido a la oración: unidad comunicativa y estructura gramatical.

5. Pero dirijamos ahora nuestra atención a ejemplos como los siguientes:
/16/ a. ¡Puag!
b. ¡Qué asco!
c. ¡Qué asco me da!
d. Esta comida me da asco.

$/ 17 /$ a. ¡Ay de mí!

b. ¡Qué desgracia!

c. ¡Qué desgraciado soy!

d. Soy un desgraciado porque nunca me llega la suerte.

Si examinamos con detenimiento estos casos, podremos comprobar que nos encontramos ante una serie de enunciados que, dentro de su grupo, son equivalentes desde el punto de vista de su significado referencial, aunque, por supuesto, cada uno de éstos manifiesta un distinto grado de énfasis y de información desde una perspectiva comunicativa. Salvando estas diferencias de énfasis, podemos decir que estamos ante una serie de alternativas, posibilidades, que da la lengua al hablante para expresarse según sus necesidades.

Pero cabe preguntarnos ahora a qué tipo de unidades, según las clasificaciones vistas hasta este momento, pertenecen cada una de estas expresiones.

. Está claro que, a nivel discursivo-comunicativo, todas y cada una de ellas conforman lo que es un enunciado, según terminología de G. Rojo, o una cláusula, según J.M. Lope Blanch, pues se caracterizan por ser unidades comunicativas y, dentro del acto de comunicación, disfrutan de plena autonomía.

Sin embargo ¿dónde quedarían situadas a nivel gramatical?

Según la clasificación de Rojo, sólo los ejemplos /16/ c y d, y /17/ c y d pertenecen al nivel gramatical, pues presentan una estructura SN+SV. Tienen, por lo tanto, estructura de cláusula.

Pero ¿qué sucede con los casos /16/ a y b, y /17/ a y b? ¿Son sólo unidades pertenecientes al nivel discursivo, quedando fuera del nivel sintáctico? $\mathrm{O}$ ¿simplemente son sintagmas, siendo así unidades de un nivel jerárquico inferior a la oración? No creemos que ninguna de estas soluciones sea válida para analizar este tipo de estructuras.

Por otra parte, según Lope Blanch, /16/ c y d, y /17/ c y d son construcciones 
oracionales pues presentan una estructura bimembre basada en la relación [S<----P].

Casos como/16/a y /17/a no tienen cabida dentro de la clasificación de este autor.

Y, por último, ejemplos del tipo de /16/ b y /17/ b conforman lo que éste llama frases, pues tiene como núcleo ordenador un nombre, pero no están estructuradas, según este lingüista, conforme al modelo [S<----P]. Queda pues como una estructura de segundo orden, una estructura marginal dentro de la lengua española.

Podríamos preguntarnos, no obstante, si la lengua nos ofrece esta serie de alternativas (construcciones interjectivas, como /16/ a y /17/a, Oraciones de Predicado no verbal, como /16/ b y /17/a, y cláusulas, según terminología de Rojo que en el presente estudio adoptaremos, como /16/ c y d, y /17/ c y d) para expresar una misma cosa, un mismo significado denotativo-referencial, ¿no es lógico que todas estas estructuras posibles estén a un mismo nivel jerárquico? Si esto es así en la jerarquía de las unidades de la lengua tendríamos lo siguiente:

\section{Enunciado}

\section{Oración}

$\begin{array}{cc}\text { Cláusula - Oraciones de Predicado } & \text { - } \begin{array}{l}\text { Construcciones } \\ \text { no verbal }\end{array} \\ \text { interjectivas }\end{array}$

Sintagma, etc.

Es decir, de la unidad Sintagma se pasaría al menos a tres unidades superiores pertenecientes al mismo nivel jerárquico: Cláusula, Construcciones de predicado no verbal e Interjecciones. La unidad superior a estas tres sería la Oración.

Esto nos parece una incoherencia que viene dada por diferentes razones:

1) Por no distinguir entre lo que es pura construcción sintáctica y lo que son las unidades lingüísticas.

2) Por intentar, ante todo, hacer coincidir lo que realmente es la oración con un tipo de estructura, la SN+SV, que, efectivamente, es la más utilizada, estadísticamente hablando, por el hablante de español, pero no es la única, quedando así una descripción parcial de la realidad lingüística.

Todo ello nos obliga a replantearnos lo que es esencialmente el concepto de oración, cuya dificultad se hace patente en definiciones como la de C. Hernández Alonso, quien pone de manifiesto el carácter de unidad intermedia entre las supraoracionales y las infratextuales que tiene ésta ${ }^{24}$.

${ }^{24}$ Según C. Hernández Alonso, en su Gramática funcional del Español (Madrid, Gredos, 1984), «la oración es un todo unitario, es una unidad lingüística con estructura propia; pero al mismo tiempo que unidad gramatical es una unidad textual o de enunciado, compuesta, generalmente, pero no necesariamente, por "nexus" y formante de "parágrafos", que posee autonomía semántica, independencia gramatical y unidad fónica». (P. 56). 
6. Analicemos cada uno de los ejemplos dados en el anterior apartado.

Los casos /16/ c y d, y /17/ c y d tienen como característica principal ser una estructura [S<----P] que se manifiesta por la relación entre un SN y un SV. En este tipo de estructura no nos detendremos pues es harto conocida.

Pero ¿qué ocurre con los demás ejemplos?

En $/ 16 /$ a y $/ 17 /$ a tenemos un tipo de construcción interjectiva ${ }^{25}$. Estas estructuras son consideradas por bastantes autores como oraciones completas, o, por lo menos, equivalentes de oración. Entre estos linguiistas están Salvá, A. Bello, Lacuerva, M. Marín, V. Lamiquiz, R. Lenz, A. Alonso, S. Gili Gaya, Barrenechea, C. Hernández Alonso, y un largo etcétera.

De construcciones como las de /17/ a dice E. Alarcos: «se presentan como unidades sintagmáticas, siempre sin pausa, que aunque funcionen como oraciones sin verbo, están reducidas a su sólo predicado (naturalmente no verbal), el cual consiste en un núcleo léxico (el primer elemento que a su vez puede funcionar aislado: ¡Ay!, ¡Pobre!, ¡Condenados!) y un término adyacente que delimita su alcance semántico (...). Tales ejemplos equivaldrían, en sustancia, a otras estructuras en que ese primer elemento funcionaría como sujeto: ¡Ay de ti! ----> «El de lamentar eres tú (...)»²6. Si, como afirma Alarcos, este tipo de construcciones equivalente a una oración está conformado por un Predicado, cuyo núcleo es el elemento interjectivo, ello quiere decir que existe un Sujeto, ya que entre Sujeto y Predicado se establece una relación de interdependencia, de manera que un Predicado no puede existir sin un Sujeto y viceversa.

Así pues, cabe replantearse en qué consiste la relación $\mathrm{S}<--->\mathrm{P}$ : ¿Es la simple relación de concordancia establecida entre un SN y un SV o, por el contrario, es una relación de tipo informativo en la que se conecta «algo de lo que se habla» con «lo que se dice sobre ese algo»? Nosotros nos decantamos por esto último, postura que ya en el siglo XVIII lanzaron lo gramáticos de Port Royal y de la que derivan teorías como la del Sujeto psicológico o la definición más actual de Sujeto gramatical como el que realiza la acción expresada por el verbo.

Por otro lado, en numerosas ocasiones «aquello de lo que se habla» o Sujeto no aparece explícito, pues por conocido por los hablantes se omite, teniendo el mensaje un mayor rendimiento infomativo.

Por consiguiente, en ejemplos como /16/ a y /17/a tenemos un Sujeto presupuesto por el hablante («Esta comida» y «Yo» en cada caso), y un Predicado explícito que conforma lo que se dice sobre el Sujeto» (Puag y ay respectivamente).

De ello se deduce que existe una relación de predicación.

\footnotetext{
${ }^{25}$ No nos detendremos aquí en definir la interjección pues la dimensión de este trabajo no nos lo permite. Sirva como punto de referencia para entender nuestro concepto de ésta la dada por V. Lamiquiz: «parte del discurso que desempeña la función de sustituto de oración o de secuencia textual. Su valor significativo se deducirá eminentemente de la situación del hablante en el discurso, pues, como sustituto que es, no tiene valor semántico fijo y la misma forma interjectiva podrá ofrecer variadas significaciones». (V. Lamiquiz, Lingüística Española (Sevilla, P.U.S., 1983), p. 375).
}

${ }^{26}$ E. Alarcos Llorach, Estudios de gramática funcional de Español (Madrid, Gredos, 1984), p. 259. 
Asimismo, en los casos $/ 16 / \mathrm{b}$ y $/ 17 / \mathrm{b}$ nos encontramos ante lo que en nuestros estudios anteriores hemos llamado Oración de Predicado no verbal que, además de características como su fuerte carga informativa (ya que sólo se dan a conocer elementos nuevos en la comunicación) y su función cohesiva y de coherencia en el texto ${ }^{27}$, tiene una peculiar manera de presentar la relación de predicación: El Sujeto puede o no aparecer, según sea conocido o no por los interlocutores, pero el predicado siempre está presente, aunque en éste no está explícito el verbo, núcleo organizador del mismo ${ }^{28}$.

Así, en estos casos tenemos «algo de lo que se habla», que, por conocido, está implícito («Esta comida» y «yo», respectivamente) y un Predicado en el cual, por la misma razón, no aparece el verbo.

Por lo tanto, en los tres tipos de estructuras analizadas la cláusula, la Oración de Predicado no verbal y la construcción interjectiva, hay un denominador común que tal vez sea el que defina a la oración como tal unidad: la autonomía sintáctica y semántica, de la cual ya hablan autores como C. Hernández Alonso («la oración es ya unidad capaz de transmitir un mensaje, un enunciado autónomo y suficiente, intencionado y comprensible. Por eso podemos decir que a partir de ella entramos en las unidades textuales o de enunciado» ${ }^{29}$ ) y la existencia de una relación establecida entre un Sujeto y un Predicado, es decir, la relación de Predicación. Esto quiere decir, a su vez, que no hay una estructura sintáctica determinada y definida para expresar dicha relación. Por el contrario, existe una variada gama de construcciones que así lo demuestra.

Todo ello nos lleva a pensar que lo realmente esencial del concepto oración, el rasgo definitorio de ésta por excelencia, es la existencia de una relación $S<--->P$, la relación entre «algo sobre lo que se habla» y «lo que se dice sobre ello», estructura que muchos autores, entre ellos M. A. K. Halliday, L. Fant o, en España, T. Jiménez Juliá y G. Rojo, han llamado función Tema-Rema ${ }^{30}$.

Según éste último, «esos dos elementos son los que en Platón o Aristóteles aparecen como constituyentes de la oración: ónoma y rema» ${ }^{31}$, pero han sido

${ }^{27}$ Para mayor claridad del tema sirva de referencia nuestra Tesis de Licenciatura titulada Las oraciones de predicado no verbal, Facultad de Filología de Sevilla, Febrero de 1989.

${ }^{28}$ En éstas se ha producido una elipsis verbal, consistente en una sustitución por $\phi$ del verbo núcleo. Pero esta elipsis no es posterior a la omisión del mensaje, sino simultánea. Es decir, yo, hablante, no pienso «Las cuentas han de estar claras», y, una vez pensado esto, aplico la elipsis y digo «Las cuentas, claras», sino que la elipsis se produce en el mismo pensamiento del hablante, pues éste tiene una intención: potenciar, enfatizar, lo verdaderamente importante.

${ }^{29}$ C. Hernández Alonso, op. cit., p. 38.

30 Aunque muchos lingüistas identifican Tema-Rema con la dicotomía Dado-Nuevo, en nuestros anteriores trabajos hemos demostrado que no es necesariamente así, pues son funciones informativas distintas. Por ejemplo:

¿Quién viene?

Juan.

En este caso, Juan es Tema y Nuevo. Lo omitido sería el Rema y la información dada o vieja. Está claro, pues, que ambos tipos de función no son, en absoluto, idénticas.

${ }^{31}$ G. Rojo, Aspectos..., op. cit., p. 90. 
olvidados tanto por la gramática tradicional, como por el Estructuralismo europeo y la Lingüística generativo-transformacional.

El Sujeto es el punto de partida de la comunicación, la base o soporte de la misma. Mientras que el Predicado es lo que se «predica» sobre esa base. Ambos elementos se encuentran en todas las estructuras que hemos analizado.

Esto nos pone en la pista de que posiblemente el concepto oración está conformado por la estructura o relación predicativa basada en criterios informativos, que es el rasgo que la caracteriza como tal. Esto implica que éste es el molde de la comunicación completa, por lo cual el criterio definidor es claramente comunicativoinformativo.

7. Por último, cabría cuestionarnos cómo una unidad gramatical, la oración, no puede ser representada por una estructura sintáctica perfectamente definida.

Para explicar esto debemos atender a conceptos que nos vienen desde la Lingüística General, como son los dados por L. Hjelmslev sobre las invariantes lingüísticas y sus variantes.

Según este autor, «si imaginamos un texto dividido en períodos, éstos en frases, éstas en palabras, etc. y un inventario por cada análisis, podremos observar que en muchos lugares del texto tenemos «un mismo» período, «una misma» frase, «una misma» palabra, etc.: puede decirse que hay muchos ejemplos de cada período, de cada frase, de cada palabra, etc. A estos ejemplos los llamaremos variantes y a las entidades de las que son ejemplos invariantes. Más aún, se observa inmediatamente que no sólo las entidades sino también las funciones tienen variantes, de modo que la distinción entre variantes e invariantes se aplica a los funtivos en general» ${ }^{32}$. Por consiguiente, de manera general, podemos afirmar que siempre que a un cambio de significado le corresponda un cambio en la expresión, o viceversa, estamos ante una invariante. Mientras que si hay un cambio de expresión y no de significado, o al contrario, tenemos una variante.

De acuerdo con ello, si tenemos varias construcciones sintácticas que, por una parte, son equivalentes en lo que se refiere a su significado óntico-referencial, aunque difieren en su grado de énfasis, y, por otra parte, responden todas ellas al concepto de Oración, nos encontramos ante una serie de variantes de una invariante: La Oración misma.

Representémoslo gráficamente para mayor claridad de la cuestión:

Invariante

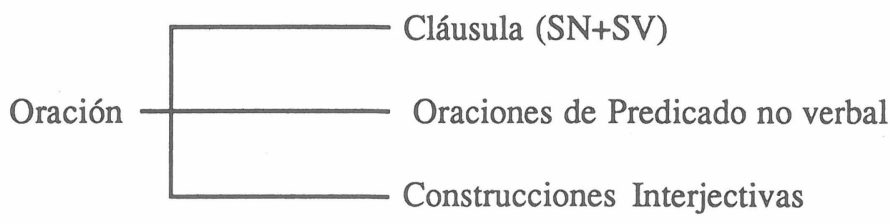

${ }^{32}$ L. Hjelmslev, Prolegómenos a una teoría del lenguaje, $2^{\mathrm{a}}$ ed. (Madrid, Gredos, 1980), pp. 91-92. 
Según este gráfico, todas estas estructuras están incluidas dentro del concepto de Oración tal y como lo hemos definido anteriormente, aunque no presentan estructura clausal, cosa, por otra parte, no necesaria para ser introducida en esta categoría.

8. De todo lo expuesto a lo largo del presente trabajo se deduce que las unidades lingüísticas se organizan según criterios de jerarquía y van desde el fonema, unidad mínima distinguidora de significado, hasta el Texto, que es la unidad global. Tradicionalmente, para clasificar estas unidades se ha utilizado el criterio constitutivo. Así pues, por ejemplo, se ha dicho que la palabra es la unidad constituida por morfemas, los morfemas por fonemas, etc.

Jerárquicamente, la oración se situaría entre el sintagma (unidad de función) y el enunciado (secuencia que responde a un sólo acto de enunciación). Es una unidad lingüística perteneciente al nivel gramatical, que se sitúa entre lo que son las unidades infratextuales, por un lado, y las supraoracionales, por otro. De éstas últimas se está ocupando actualmente la Teoría del Texto o Linguiística Textual, que va abriendo vías nuevas para un más completo análisis de la realidad lingüística.

Como hemos podido observar, en los últimos tiempos, la oración ha sido definida preferentemente según el punto de vista gramatical, olvidando que, por ser unidad linguiistica, también ha de ser caracterizada, aunque no exclusivamente, según los criterios semántico, fonológico e incluso informativo. De ahí que las definiciones que no tengan en cuenta todos estos criterios serán claramente insuficientes.

De acuerdo con estos principios nosotros hemos intentado ofrecer en este estudio un concepto de oración en el que tenga cabida cada uno de estos aspectos. De esta forma, podemos decir que:

-La oración se caracteriza principal y esencialmente por presentar una relación de predicación, Sujeto-Predicado, basada en criterios informativos, pues es la relación entre «algo de lo que se habla» y «lo que se dice sobre ello». Este viene a ser, a nuestro juicio, el rasgo definitorio de esta unidad.

-Desde el punto de vista semántico, presenta un significado completo, pues expresa un mensaje autónomo y suficiente.

-Según criterios fonológicos, la oración se caracteriza por ser una unidad fónica.

-Esa relación de predicación que conforma la oración viene expresada, sintácticamente, por diversas estructuras, como son la estructura clausal ( $\mathrm{SN}+\mathrm{SV})$, la oración de predicado no verbal (u oración sin verbo), la interjección, etc., que se erigen, por lo tanto, como variantes estructurales y contextuales de la unidad oracional. Esta, por otro lado, queda establecida como una invariante linguística, definida por esa relación de carácter informativo que es la predicatividad.

Somos conscientes de que la definición que se ha dado en este estudio de Oración no es, en modo alguno, suficiente, ya que un tema como el que aquí tratamos precisa un mayor detenimiento que, debido a las propias limitaciones impuestas por un trabajo de esta naturaleza, nos ha sido imposible, quedando éste para tarea de nuestras futuras investigaciones. 